NASA Technical Memorandum 101483

\title{
Channelized Coplanar Waveguide: Discontinuities, Junctions, and Propagation Characteristics
}

Rainee N. Simons

Case Western Reserve University

Cleveland, Ohio

and

George E. Ponchak, Konstantinos S. Martzaklis, and Robert R. Romanofsky Lewis Research Center

Cleveland, Ohio

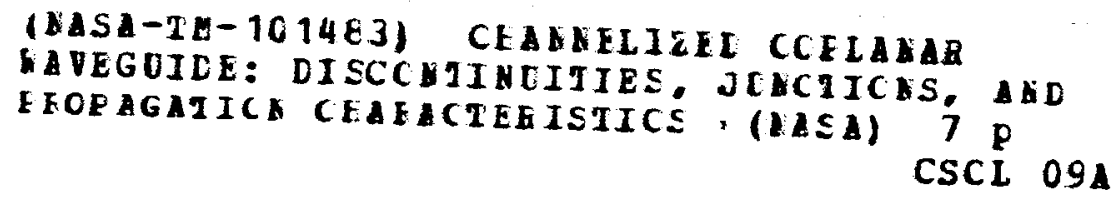

0158499

Prepared for the 1989 IEEE MTT-S International Microwave Symposium Long Beach, California, June 13-15, 1989

\section{N/SA}


CHANNELIZED COPLANAR WAVEGUIDE: DISCONTINUITIES, JUNCTIONS, AND PROPAGATION CHARACTERISTICS

Rainee N. Simons

Case Western Reserve University

Cleveland, Ohio 44106

and

George $E$. Ponchak, Konstantinos S. Martzaklis, ${ }^{\dagger}$ and Robert R. Romanofsky

National Aeronautics and Space Administration

Lewis Research Center

Cleveland, Ohio 44135

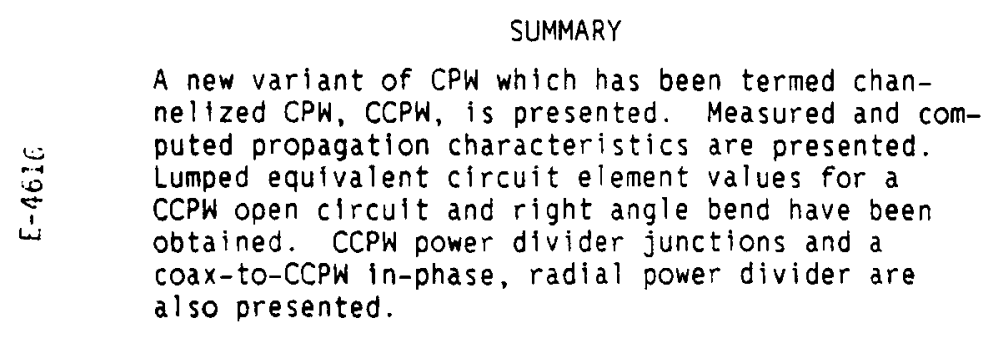

INTRODUCTION

Coplanar waveguide, CPW, on a dielectric substrate consists of a center strip conductor with semi-infinite ground planes on either side (1). A varlant of $\mathrm{CPW}$ is grounded coplanar waveguide. GCPW, which has an additional ground plane on the opposite side of the substrate to factlitate heat removal and packaging (2). These transmission lines have several advantages which make them tdeally suited for microwave integrated circuits. The disadvantage of CPW and GCPW is that the strueture can support spurious modes besides the CPW mode since the transverse dimensions may be several wavelengths.

This paper presents a new variant of CPW. The new structure has side walls which, together with the ground plane, constitutes a channel and hence is appropriately termed as channelized coplanar waveguide, CCPW. A shielding structure may be used to further confine the electromagnetic fields. This structure is shown in Fig. 1. The enclosure of the CPW transmission line eliminates radiation loss and spurious surface modes created at discontinulties. Also, because the basic transmission line structure is $\mathrm{CPW}$. CCPW maintains the inherent advantages over microstrip for easy shunt as well as series mounting of active and passive components.

To maintain a single CPW mode of propagation, CCPW must be designed to suppress the dielectric filled rectangular waveguide mode, the microstrip mode, and the rectangular coax mode. The channel width, 28, is chosen such that the rectangular waveguide mode is cutoff. The microstrip and rectangular coax modes are suppressed by the proper selection of the slot width. $W$, the center strip

"NASA Resident Research Associate.

tPresently at the University of Akron, Akron, Ohio 44325 . width, S, and the substrate thickness, 0 . The ratios $W / D$ and $S / D$ must be sufficientiy small to suppress the microstrip mode. The ratio $\mathrm{W} / \mathrm{B}$ must be small to suppress the rectangular coax mode.

This paper presents lumped element circuit models for several CCPW discontinuities, together with their element values as a function of frequency. The discontinuities characterized are an open circuit and a right angle bend. The measured frequency dependence of the effective dielectric constant, $\varepsilon$ (eff), and the unloaded quality factor, $Q$, are also presented for CCPW IInes fabricated on $\varepsilon(r)=2.2 \pm 0.02 \mathrm{RT} /$ Duroid $5880, \varepsilon(r)=6.0 \pm 0.15 \mathrm{RT} /$ Duroid 6006, and $\varepsilon(r)=10.2 \pm 0.25$ 3M Epsilam-io substrates. This is followed by the design and characterization of a CCPW T-junction and 1-to-3 in-phase, matched power divider. Lastly, the performance of a novel Coax-to-CCPW in-phase, N-way radial power divider circuit is presented.

\section{METHOD OF MEASUREMENTS}

A resonator technique similar to that described by Richings ( 3 ) and Stephenson and Easter (4) was used. The $\lambda / 4$ end coupled stubs could not be etched off as in the case of microstrip since this would alter the CCPW open end parameters. Hence, a four resonator set had to be fabricated for each frequency to determine the end effects. This will contribute some errors to the results because the resonator lengths and gaps will not be identical for the two $\lambda / 2$ and $\lambda$ resonators. The circuit dimensions were measured to $=0.0002 \mathrm{in}$. The gaps were varied to maintain a coupling coefficient, $\beta$, less than 1 . For most of the resonator sets $\beta<0.3$. This is a sufficient condition to minimize the loading of the resonator for transmission lines with $Q^{\prime} S$, 100 as are reported in this paper. The $Q$ was determined through a technique given in Ref. 5.

\section{EFFECTIVE DIELECTRIC CONSTANT}

The $\varepsilon$ (eff) was measured over the frequency range of 3 to $18 \mathrm{GHz}$ for several unshlelded CCPW lines and the results are shown in Fig. 2. The CCPW lines have been modeled using Cohn's technique (6) and the $\varepsilon$ (eff) is plotted for each CCPW line. $\varepsilon$ (eff) of grounded $C P W$ calculated from the closed form expression of Ghoine and $\mathrm{Naldi}$ (7) is also plotted for comparison. 


\section{ORIGINAL PAGE IS \\ OF POOR QUALITY}

Efort of juostrate Thickness

$\varepsilon(e f f)$ was measured for unshielded CCPW lines fabricated on substrates with $D$ in the range of 0.062 to $0.250 \mathrm{in}$. The CCPW parameters 5 . $W$, 28 , and $\varepsilon(r)$ were held fixed at $0.045,0.010$. 0.200 , and 2.2 in. respectively. No variation in e(eff) was observed for the thicker substrates, W/D $\leqslant 1 / 12.5$. $\varepsilon$ (eff) of the thinner substrate, $W / D \equiv 1 / 6$, was 0.7 percent higher than the other measured cases; this may be due to the microstrip mode.

\section{Effect of Cover Height}

E(eff) was measured for shielded CCPW lines with cover heights of $H=D, 20$, and 40 . Resondtors were tested with $\varepsilon(r), D, S$, and $W$ equal to $2.2,0.125,0.045$, and $0.010 \mathrm{in}$. respectively. Resonators were aiso fabricated on $D=0.050 \mathrm{in}$. $\varepsilon(r)=6$ and 10.2 substrates. In all the cases. the change in $\varepsilon$ (eff) from the unshielded case was negligible.

\section{LOSS MEASUREMENTS}

Figure 3 shows the measured $Q$ for resonators of length $\lambda$ as a function of $S$ for a fixed frequency and $\varepsilon(r)$. The $Q$ of the unshielded resonators decreases with increasing $S$ indicating an increase in radiation loss. The shielding enclosure eliminates the radiation loss as evidenced by the higher $Q$.

Figure 4 shows the measured $Q$ over the frequency range of 3 to $18 \mathrm{GHz}$ for $\lambda$ resonators both with and without shielding. The reduction in $Q$ with increasing frequency for the unshielded case is due to the increase in radiation loss. With shielding, the $Q$ is observed to increase with frequency due to the reduction of radiation loss. A change in the cover height from $H=20$ to $H=D$ showed no measurable difference in $Q$. The effect of varying $D$ in the range of 0.062 to 0.250 in on $Q$ was measured. No measurable variation in $Q$ over the frequency range of 8 to $18 \mathrm{GHz}$ was observed.

\section{OPEN END LINE EXTENSION}

When a CPW line is terminated in an open circult, there is an excess fringing of the electromagnetic fields which gives rise to a capacitance, Cf ( 8 ). This capacitance is equivalent to a short length of a transmission line, Lo, terminated in a perfect open circuit. The open end line extension for the unshielded CCPW de-embedded from the resonator data is shown as a function of frequency in Fig. 5. There was no variation in Lo for resonators with a cover height of $H \geq 20$.

\section{RIGHT ANGLE BEND}

A CCPW right angle bend and its equivalent circuit are shown in Fig. 6. The capacitance, $C$, is created by the accumulation of excess charge at the corners in the two slots and the resulting excess electric fields to the ground plane. The current flow interruption creates the excess indurtance which can be equated to a length of transmision line. L. Radiation from the corner is represented by the shunt resistance. The equivalent circuit parameters were found through resonator techniques and are shown in Table I.

\section{CHANNELIZED CPW MATCHED T-JUNCTION}

A CCPW matched T-junction was faoricated. At the T-junction, the characteristic impedance, 21 , of the two side arms are in parallel and the net impedence the input arm sees is $21 / 2$. Therefore, for impedance matching, the characteristic impedance, 20 , of the feed line was set equal to $21 / 2$ The insertion loss of the junction, including test fixture loss, is $0.5 \mathrm{~dB}$ and the return loss is greater than $10 \mathrm{~dB}$ from 3 to $6 \mathrm{GHz}$.

\section{CHANNELIZED CPW MATCHED 1-TO-3 IN-PHASE POWER DIVIOER}

A CCPW matched 1-to-3 in-phase power divider was faoricated. An important requirement for a power divider is that the signal emerging from the output ports is in phase. In order to achleve this, the path length between the side arms and the thru arm must be equalized. This is achleved by tapering the center conductors of the three output $l$ ines and the input line so they meet at a point. The taper also facilitates impedance matching of the input port to the output ports. For the octave bandwidth of 3 to $6 \mathrm{GHz}$, a maximum amplitude imbalance of 1 dB was measured. The isolation between output ports was $9 \mathrm{~dB}$ and the input return loss was greater than $10 \mathrm{~dB}$.

\section{COAX-TO-CHANNELIZED CPW IN-PHASE N-WAY RADIAL POWER DIVIDER}

A coax-to-CCPW in-phase, four-way radial power divider is shown in $\mathrm{Fig} .7$. The junction is formed by the intersection of four CCPW lines. Power is coupled to this junction from a coaxial cable whose outer conductor is slotted along the $\vec{z}$ direction to form four coupled transmission lines. The center pin of the coaxial line meets the intersecting CCPW center conductors whlle the four coupled outer conductors meet the CCPW ground planes. Therefore, the electric current at the open end of the coax is divided into the four CCPW lines as illustrated in Fig. 8. This arrangement has the advantage of holding ground planes at the same potential and exciting the four $C P W$ ines in equal amplitude and phase. The amplitude and the phase balance for this circuit over a 2 to $18 \mathrm{GHz}$ band are within $0.5 \mathrm{~dB}$ and $1^{\circ}$ respectively; the isolation $1 \mathrm{~s} 10 \mathrm{~dB}$ between the output ports.

\section{CONCLUSIONS}

This paper presents a new variant of CPW which has been termed CCPW. Measured propagation characteristics for CCPW are presented and compared with computed values. Equivalent circuit component values are presented for an open circuit and a right angle bend. CCPW power divider junctions and a novel coax-to-CCPW in-phase, radial power divider are also described. 


\section{REFERENCES}

1. C.P. Wen, "Coplanar Waveguide: A Surface Strip Transmission Line Sultable for Nonreciprocal Gyromagnetic Device Applications," IEEE Trans. Microwave Theory Tech., vol. MTT-17, no. 12, pp. 1087-1090, Dec. 1969.

2. Y.C. Shih, and T. Itoh, "Analys is of Conductor-Backed Coplanar Waveguide," Electron. Lett., vol. 18, no. 12 , PP. 538-540, June 10, 1982 .

3. J.G. Richings, "An Accurate Experimental Method for Determining the Important Properties of Microstrip Transmission Lines," The Marconi Review, vol. 37, no. 195. pp. 209-216, Fourth Quarter 1974.

4. I.M. Stephenson, and B. Easter, "Resonant Techniques for Establishing the Equivalent Circuits of Small Discontinuities in Microstrip." Electron. Lett., vol. 7, no. 10, pp. 582-584, Sept. 23, 1971 .
R.R. Romanofsky, "Analytical Procedures and Experimental Techniques for Determining Propagation Characteristics of $\mathrm{mm}$-Wave Microstrip Lines," NASA TP-2899, 1989.

6. R.N. Simons, "Suspended Coupled Siotline Using Double Layer Dielectric." IEEE Trans. Microwave Theory Tech., vol. MTT-29, no. 2, pp. 162-165, Feb. 1981.

7. G. Ghione and C. Naldi, "Parameters of Coplanar Waveguides wi th Lower Ground Plane," Electron. Lett., vol. 19, no. 18, pp. 734-735, Sept. 1, 1983.

8. R.N. Simons and G.E. Ponchak, "Modeling of Some Coplanar Waveguide Discontinuities," IEEE Trans. Microwave Theory Tech., vol. 36 , no. 12, pp. 1796-1803, Dec. 1988.

TABLE I. - CPW RIGHT ANGLE BEND DISCONTINUITY

[ $(S=0.045 \mathrm{in} ., W=0.010 \mathrm{in} ., \varepsilon(r)=2.2$, $2 B=0.200$ in.). $]$

\begin{tabular}{|c|c|c|c|}
\hline $\begin{array}{c}\text { Frequency, } \\
\text { GHz }\end{array}$ & $\begin{array}{c}\mathrm{L}, \\
\mathrm{mil}\end{array}$ & $\begin{array}{c}\mathrm{C} / \mathrm{YO}_{\mathrm{O}}, \\
\mathrm{pF} \cdot \Omega\end{array}$ & $\begin{array}{c}\mathrm{Q}, \\
\text { radiation }\end{array}$ \\
\hline 2.97 & 22.622 & 4.219 & $\infty$ \\
4.92 & 26.241 & 4.353 & $53,142.5$ \\
9.74 & 30.972 & 3.192 & 245.18 \\
13.49 & 27.867 & 2.950 & 122.70 \\
17.84 & 31.794 & 3.848 & 237.6 \\
\hline
\end{tabular}




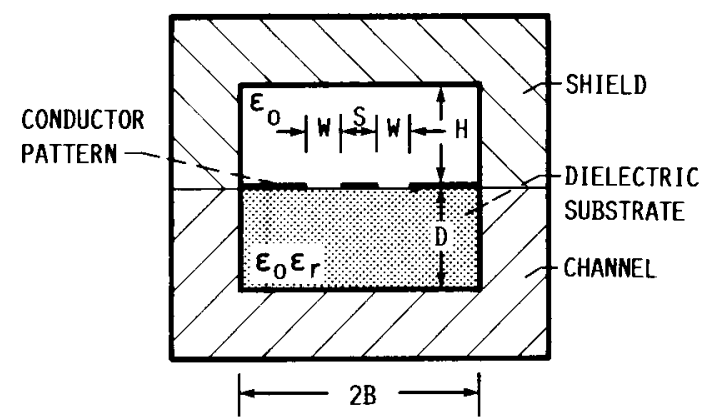

FIGURE 1. - SCHEMATIC ILLUSTRATING A CHANNELIZED COPLANAR WAVEGUIDE (CCPW).

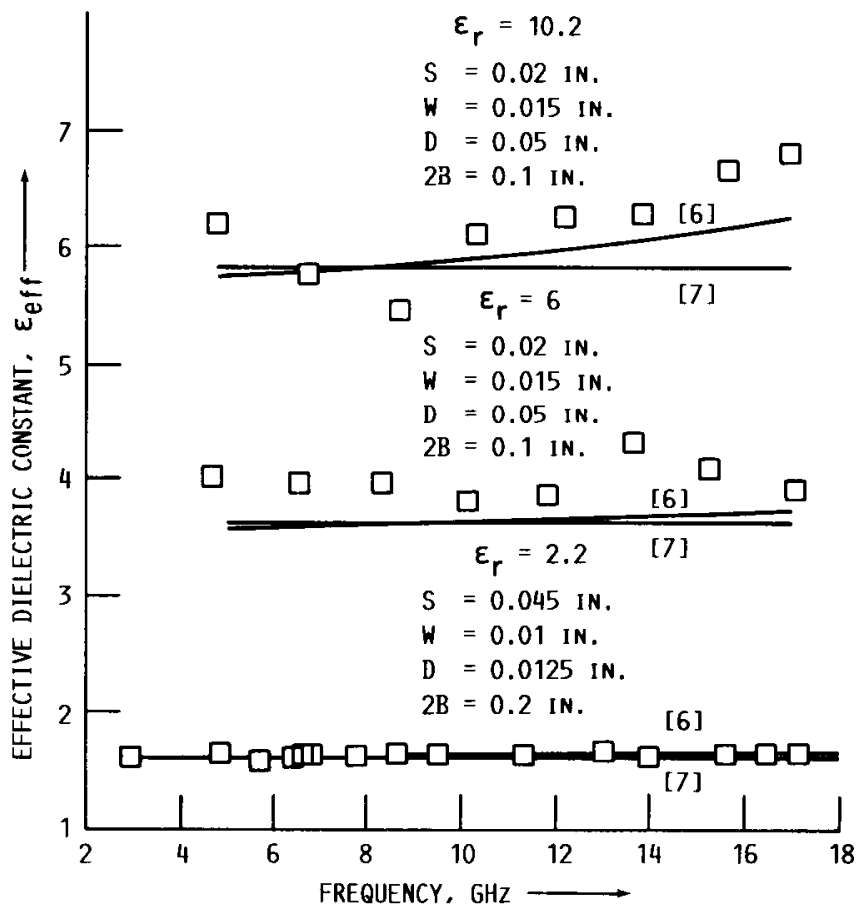

FIGURE 2. - MEASURED EFFECTIVE DIELECTRIC CONSTANT FOR THE UNSHIELDED CHANNELIZED CPW AS A FUNCTION OF THE FREQUENCY.

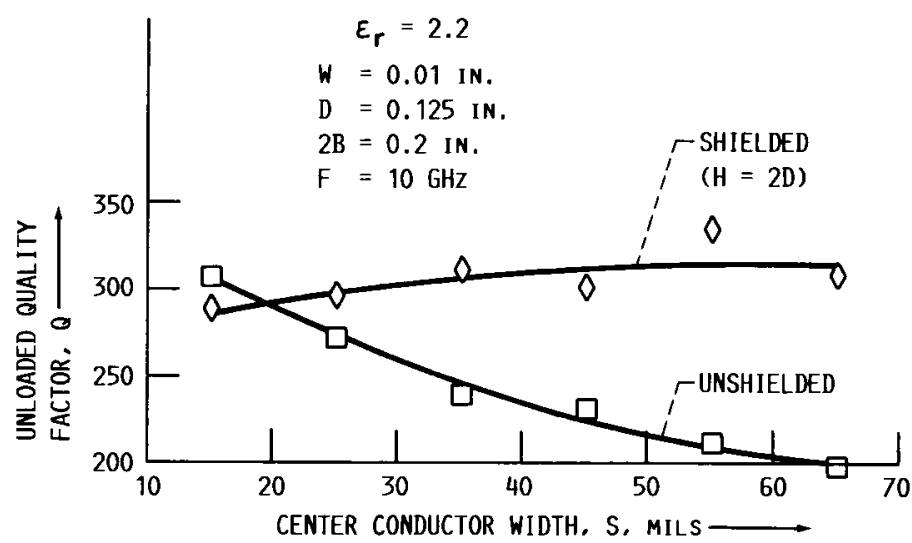

FIGURE 3. - MEASURED UNLOADED QUALITY FACTOR Q FOR CHANNELIZED CPW AS A FUNCTION OF THE CENTER CONDUCTOR WIDTH, WITH AND WITHOUT A SHIELDING ENCLOSURE. 


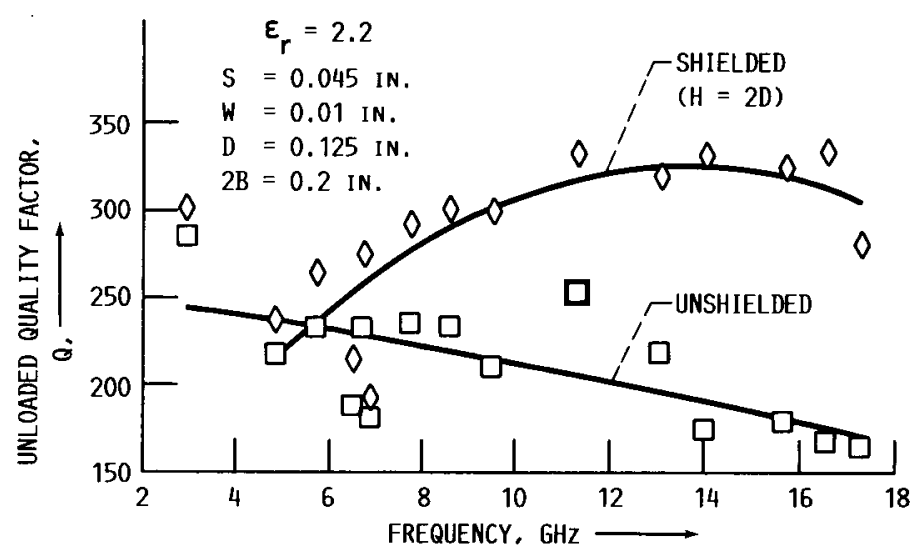

FIGURE 4. - MEASURED UNLOADED QUALITY FACTOR Q FOR CHANNELIZED CPW AS A FUNCTION OF THE FREQUENCY, WITH AND WITHOUT SHIELDING.

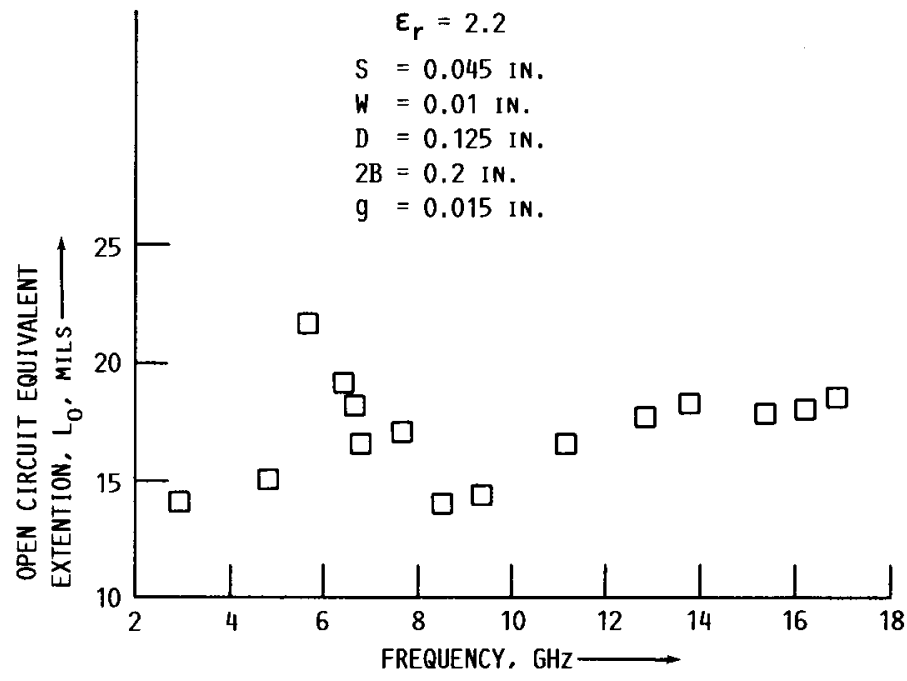

FIGURE 5. - EXPERIMENTALLY DETERMINED OPEN CIRCUIT EQUIVALENT END-EFFECT LENGTH AS A FUNCTION OF THE FREQUENCY.

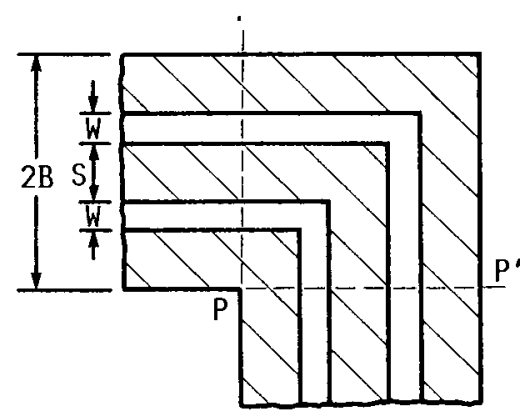

(A)

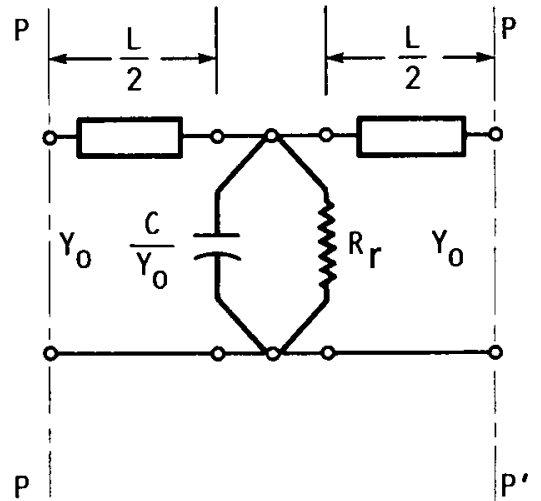

(B)

FIGURE 6. - SCHEMATIC. (A) A CHANNEL IZED CPW RIGHT-ANGLED BEND,

(B) LUMPED EQUIVALENT CIRCUIT FOR THE BEND. 


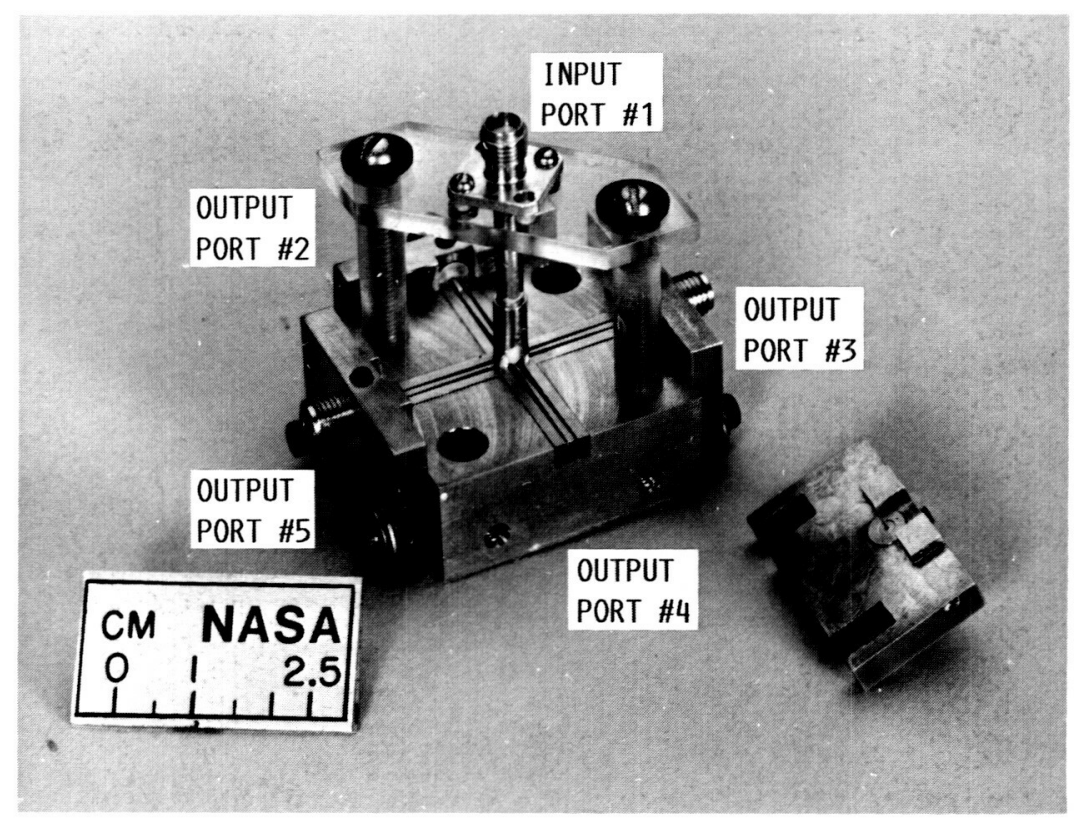

FIGURE 7. - COAX-TO-CHANNELIZED CPW IN-PHASE, FOUR-WAY, RADIAL POWER DIVIDER, ASSEMBLED VIEW.

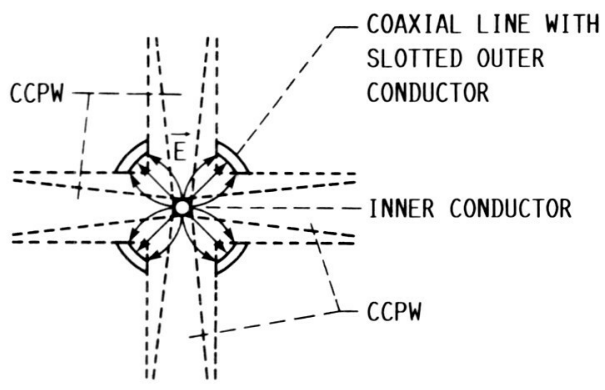

(A)

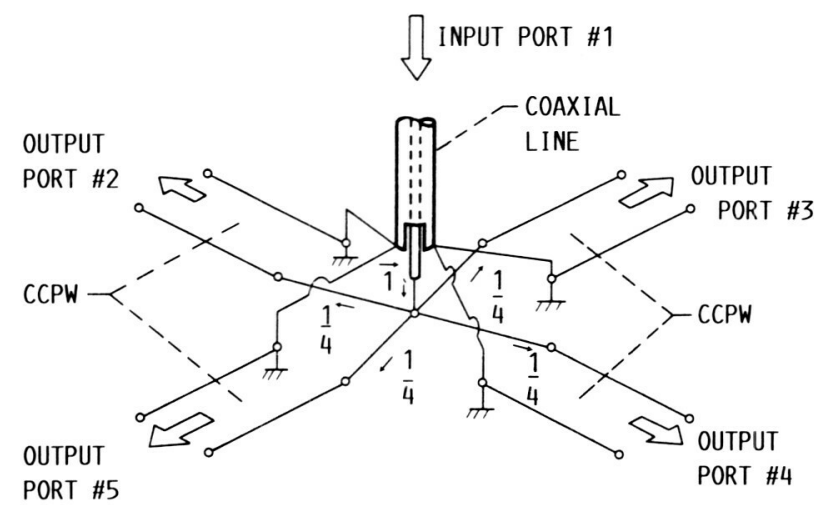

(B)

FIGURE 8. - ELECTRIC FIELD ( $\vec{E})$ DISTRIBUTION AT THE END OF THE SLOTTED COAXIAL LINE, EQUIVALENT CIRCUIT OF THE JUNCTION SHOWING THE INPUT RF CURRENT ( $\overrightarrow{\mathrm{I}}$ ) BEING DIVIDED INTO THE FOUR PORTS. 


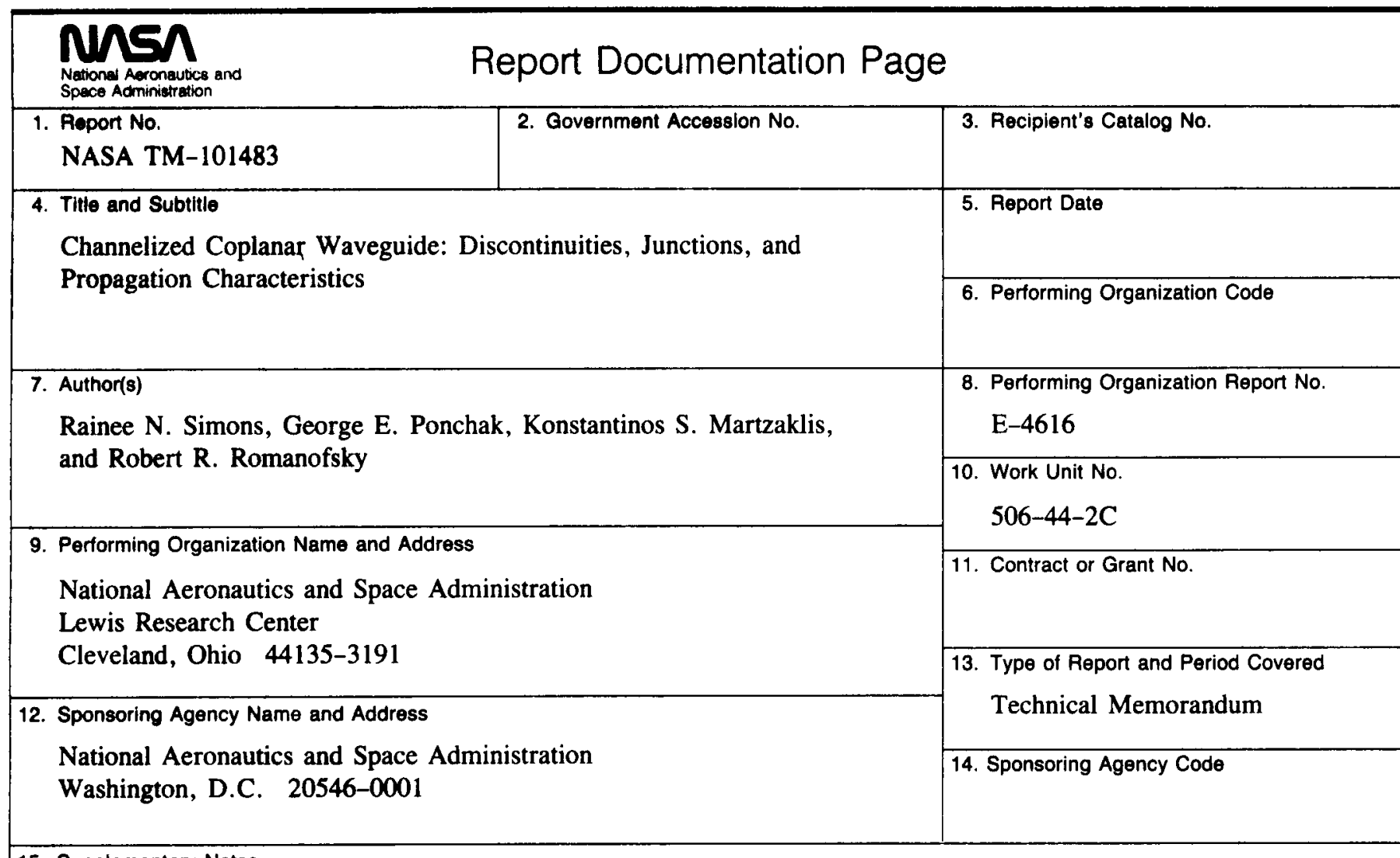

15. Supplementary Notes

Prepared for the 1989 IEEE MTT-S International Microwave Symposium, Long Beach, California, June 13-15, 1989. Rainee S. Simons, Case Western Reserve University, Cleveland, Ohio 44106 and NASA Resident Research Associate. George E. Ponchak and Robert R. Romanofsky, NASA Lewis Research Center. Konstantinos S. Martzaklis, NASA Lewis Research Center, presently at The University of Akron, Akron, Ohio 44325.

16. Abstract

A new variant of CPW which has been termed channelized CPW, CCPW, is presented. Measured and computed propagation characteristics are presented. Lumped equivalent circuit element values for a CCPW open circuit and right angle bend have been obtained. CCPW power divider junctions and a coax-to-CCPW in-phase, radial power divider are also presented.

17. Key Words (Suggested by Author(s))

Microwave transmission line

Coplanar transmission line

Power divider

Discontinuities
18. Distribution Statement

Unclassified-Unlimited

Subject Category

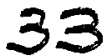

19. Security Classif. (of this report)

Unclassified
20. Security Classif. (of this page)

Unclassified
21. No of pages

8
22. Price* $\mathrm{AO2}$ 